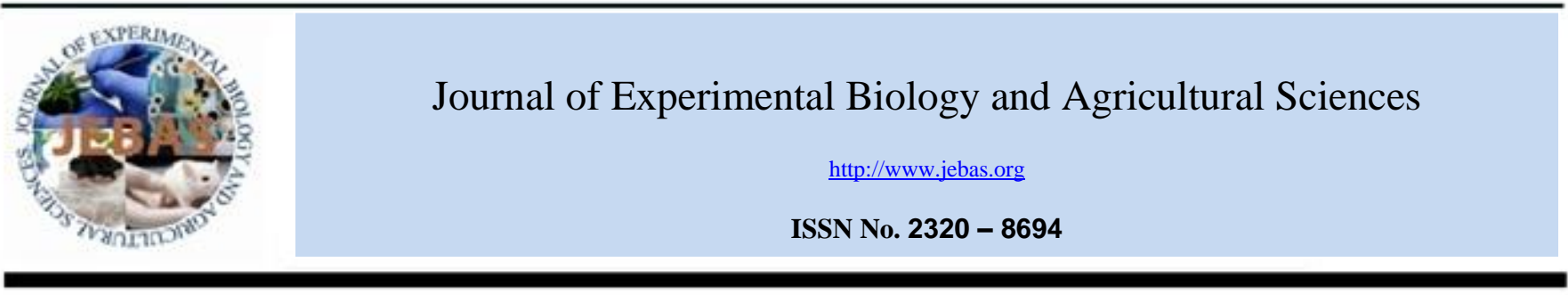

\title{
AN OVERVIEW ON THE FUNCTIONAL FOOD CONCEPT: PROSPECTIVES AND APPLIED RESEARCHES IN PROBIOTICS, PREBIOTICS AND SYNBIOTICS
}

\section{Vincenzo Tufarelli* and Vito Laudadio}

Department of Emergency and Organ Transplantation (DETO), Section of Veterinary Science and Animal Production, University of Study of Bari 'Aldo Moro', Valenzano 70010 Bari, Italy.

Received - April 18, 2016; Revision - April 25, 2016; Accepted - May 21, 2016

Available Online - May 25, 2016

DOI: http://dx.doi.org/10.18006/2016.4(3S).273.278

\begin{abstract}
KEYWORDS
Probiotics

Prebiotics

Synbiotics

Functional food

ABSTRACT

The principal role of diet is to supply adequate nutrients providing energy to sustain physiologic functions and well-being. Every foods and feeds are functional and consumption of bioactive molecules is facilitated by diet. All probiotics, prebiotics and synbiotics are functional components able to exercise significant influences on human and animal wellbeing. Emphasizing these positive activities is one possible approach for improving the health image of meat and plants and developing functional products. Discovering of new prebiotic/probiotic/synbiotic functional foods is linked to the interest of the food industry to renew constantly through introduction of products with enhanced nutritional value, but also with health advantage for consumers. This review provides potential benefits of representative bioactive compounds on human and animal health and an overview of meat and plant-based functional products. Besides the increase of scientific reports, there is a necessary need to update consumers of the feeding value of novel functional foods.
\end{abstract}

* Corresponding author

E-mail: vincenzo.tufarelli@uniba.it (Vincenzo Tufarelli)

Peer review under responsibility of Journal of Experimental Biology and Agricultural Sciences.

Production and Hosting by Horizon Publisher India [HPI] (http://www.horizonpublisherindia.in/).

All rights reserved.
All the article published by Journal of Experimental Biology and Agricultural Sciences is licensed under a Creative Commons Attribution-NonCommercial 4.0 International License Based on a work at www.jebas.org.

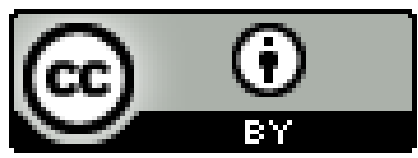




\section{Introduction}

Within the last decade, knowledge of the significance of diet in human and animal health and well-being has considerably increased and nutritionists have identified specific foods playing a key-role in supporting the consumers' health status. Beyond meeting nutritional requirements, it is extensively recognized that dietary factors are able to change the detrimental development of different chronic diseases (Alkerwi, 2014; Peiretti et al., 2015). In the developed world, there has been an explosion of consumer attention in the active role of foods in the well-being and life prolongation as well as in the prevention of initiation, promotion and development of cancer, cardiovascular diseases and osteoporosis (Pandey \& Rizvi, 2009). As a result, a new term "functional food" was proposed (Dimer \& Gibson, 1998; Sanders, 1998; Pisulewski \& Kostogrys, 2003; Grajek et al., 2005).

Functional foods may improve the overall conditions of body, reduce the risk of some diseases and could even be used for curing some illnesses (Laudadio et al., 2015). It was demonstrated that there is a high demand for functional food as many studies reported that the medical service of the aging population is quite costly (Menrad, 2003; Mark-Herbert, 2004; Side, 2006).

The concept of functional food was first defined by researchers in Japan in 1984 who investigated the correlations between nutrition, sensory quality, and physiological systems modulation (Siro et al., 2008). Later, the Ministry of Health introduced in 1991 the regulations for approval of a detailed health-related food class named Food for Specified Health Uses (FOSHU) including the institution of definite health claims for this food (Kwak \& Jukes, 2001; Menrad, 2003; Siro et al., 2008). According to Gibson \& Williams, (2005) the unique features of functional foods are

- $\quad$ being a conventional or everyday food;

- to be consumed as part of the normal/usual diet;

- composed of naturally occurring (as opposed to synthetic) components perhaps in unnatural concentration or present in foods that would not normally supply them;

- $\quad$ having a positive effect on target function(s) beyond nutritive value/basic nutrition;

- may enhance well-being and health and/or reduce the risk of disease or provide health benefits so as to improve the quality of life including physical, psychological and behavioral performances;

- $\quad$ have authorized and scientifically based claims

There is no precise legislative definition in many countries related to the term and drawing a border line between conventional food and functional food is demanding even for scientists of nutrition and food (Mark-Herbert, 2004; Niva, 2007). Up to now, a number of national authorities and academic institutions have proposed the description for functional food. The European Commission's Concerted Action on Functional Food Science in Europe (FuFoSE), directed by the International Life Science Institute (ILSI) Europe described functional food as a product that can be only considered functional if belong the basic nutritional effect it has positive influences on one or more functions to human organism, diminishing the risk of the development of diseases. However, the European Legislation, does not take into account functional foods as specific categories, but only as a concept (Stanton et al., 2005; Coppens et al., 2006).

In agreement to the European Union rule on health claims made on foods (EC No. 1924/2006), a record of official claims has to be published for all member countries, and nutrient specifications also has to be defined for food having health claims. Health claims can be "function claims" and "reduction of disease risk claims". Thus, to better understand functional food it is first essential to comprehend how the science of nutrition itself has changed. Nutrition has progressed from the prevention of nutritional deficit and the institution of dietary standards, guidelines and food/feed guides, to the support of a state of health and the reduction of the risk of disease (Siro et al., 2008; Bigliardi \& Galati, 2013; Vella et al., 2013; Vella et al., 2014; Asher \& Sassone-Corsi, 2015).

\section{Probiotics}

Based on the currently established definition by FAO/WHO in 2001, probiotics are defined as "live microorganisms which when administered in adequate amount confer a health benefits on the host". Using fermented food leads to helpful bacteria and bacterium dietary supplements, consumers are supplied with live bacteria that pass the gastric to replicate themselves in the large intestine (Michalak \& Chojnacka, 2016).

The researches sustaining the efficacy of live bacteria are copious, and there are a small amount of contradictory results on the effects of the same strain supplied in either viable or nonviable form. As a result, due to well-established definitions and for the sake of better information to consumers, the term probiotic is to be reserved for a product including vital and living cells (Aureli et al., 2011).

Probiotics that are commonly used are Lactobacilli, and Bifidobacteria as well as nonpathogenic yeast. The Bifidobacteria have been used also in microbial food supplements destined to infants (Milner \& Roberfroid, 1999), individually (Langhendries et al., 1995) or along with Lactobacilli (Marteau et al., 1997; Jahromi et al., 2015). Other microorganisms have probiotic properties such as: Escherichia coli Nissle, Streptococcus thermophilus, Enterococcus francium, Saccharomyces boulardii, Propionibacterium, Leuconostoc, and Pediococcus, however some of these strains can be pathogenic (Seno et al., 2005).

Earlier available reviestudiesws have reported that probiotics can excite the immune system (Tasvac, 1964; Rezaei et al., 
2015), decrease the intolerance to lactose (Conway, 1996), diminish incidence of diarrhea, reduce blood cholesterol (Fernandes \& Shahani, 1990) operate as a antibiotic, repress tumors and defend against cancer by sustaining the adequate balance of the intestinal microflora (Lee \& Salminen, 1995).

To achieve a probiotic status, microorganisms must fulfill a number of criteria related to safety, functional effects and technological properties (FAO/WHO, 2001). From the safety point of view, the probiotic microorganisms should not be pathogenic, have no connection with diarrhoeagenic bacteria and no ability to transfer antibiotic resistance genes, as well as be able to maintain genetic stability (Saarela et al., 2002).

In the literature, the use of different solid surface models, such as mucosa, alginate, carrageenan, gelatin, collagen, glass, polystyrene and carboxymethylcellulose are also described (An \& Friedman, 1997). However, numerous investigations have shown that none of the simple models exhibit comparable adhesion properties to those presented by epithelial cell cultures. It should be stressed that the results obtained with the in vitro models are not sufficient and require confirmation in double blind, randomized, placebo-controlled human trials.

From the practical point of view, the technological aspects of probiotic production also play a very important role. During the technological processing bacteria cells are exposed to different stresses (Knorr 1998; Mattila-Sandholm et al., 2002).

\section{Prebiotics}

According to the most recent definition "A prebiotic is a selectively fermented ingredient that allows specific changes, both in the composition and/or activity in the gastrointestinal microbiota that confers benefits upon host well-being and health" (Gibson et al., 2004; Macfarlane et al., 2006). Many criteria have to be rewarded when a molecule is to be defined as a prebiotic: stability, safety, resistance to digestion in the upper bowel and fermentability in the colon, organoleptic property, and ability to improve the growth of useful bacteria in gut (Gibson et al., 2004; Chen et al., 2014).

Carbohydrates as oligofructose, inulin, fructo-oligosaccharides (FOS), galacto-oligosaccharides (GOS), soybeanoligosaccharides, transgalacto-oligosaccharides, glucooligosaccharides, gentio-oligosaccharides, xylooligosaccharides, lactulose, isomalto-oligosaccharides, and polysaccharides as pectins and starch are considered to be efficient prebiotic substances (de Vrese \& Schrezenmeir, 2008). Nevertheless, most of the studies on prebiotics investigated the inulin-type fructans (inulin, FOS) and GOS which selectively stimulate the Bifidobacteria growth and have been related to long-lasting safe commercial utilize (Macfarlane et al., 2006; Brown et al., 2015; Rezaei et al., 2015).

A prebiotic is a non-viable food constituent moving the colon and having a selective fermentation. The advantage to host is mediated throughout a selective stimulus of growth or activity of one or a restricted number of colonic bacteria. Food ingredients classified as prebiotics must not be hydrolyzed or absorbed in the upper gastro-intestinal tract, need to be a selective substrate for one or a limited number of colonic bacteria, must alter the microbiota in the colon to a healthier composition and should induce luminal or systematic effects that are beneficial to host health (Gibson \& Roberfroid, 1995). Bifidobacteria and/or lactobacilli are good target organisms.

Thus, the plan of future investigations to study the outcome of prebiotics in both humans and animals should consider the length of supplementation period, the choice of populations, and the type of vehicle utilized to augment the prebiotics consumption in diet, as these variables may have effect on the outcome of the studies.

\section{Synbiotics}

A synbiotic is defined as: "A mixture of a prebiotic and a probiotic that beneficially affects the host by enhancing the survival and the implantation of live microbial dietary supplements in the gut, by selectively stimulating growth and/or activating the metabolism of a specific or few number of health-promoting bacteria" (Gibson \& Roberfroid, 1995; Roberfroid, 2002). Consequently, a synbiotic is a combination of the concept of probiotics and prebiotics (Mousavi et al., 2015). This mix would benefit the host by improving survival and implantation of the selected microbial supplements. Because of the nutritional benefits associated with microflora management approaches, foods are the main vehicle for pro-, pre- and synbiotics. However, there may also be potential pharmaceutical applications, but to date most evidence for this is still hypothetical.

The synbiotics offer a additional option; in fact, the employ of synbiotics as functional food components is a novel and increasing area and few animal and human studies have been conducted to investigate their outcome on risk factors for coronary heart disease (Roberfroid, 2002).

The synbiotics development is a worthwhile area of enhanced functional food compounds. Scientists are intensely interested in synbiotic theory as it leads to the combination of probiotics and prebiotics. The influence of synbiotic is directed towards two different target traits of the gut, both the small and large intestinal tracts. Prebiotic oligosaccharides stimulate probiotic bacteria in the colon, moreover prebiotic carbohydrate is used by a probiotic strain for its growth and replication in gut will be selectively supported (Deng et al., 2015). This mixture could enhance the survival of probiotic organisms, due to its specific substrate is promptly available for fermentations, determining healthier host composition.

There are many evidences related to animal investigations on the potential positive effects of synbiotics: in one of the comparative in vitro studies of a number of strains of Bifidobacterium longum, Bifidobacterium animalis and 
Bifidobacterium catenulatum grew best on FOS with much more lower growth rate found on inulin. Specific synbiotics were supplied to rat or chicken and their faeces were characterized for coliforms, bifidobacteria, and total cell counts (Mousavi et al., 2015; González-Herrera et al., 2015; Paturi et al., 2015). Higher levels of Coliforms and Bifidobacteria were found in animals fed both FOS and synbiotics (Bielecka et al., 2002). Synbiotics are believed to amplify the persistence of probiotics in gut was supported by studies including the preparation of Lactobacillus acidophilus and FOS has been investigated as in vitro model of human gut (Gmeiner et al., 2000).

Moreover, it has been believed that synbiotics consumption decrease cancer risk factors in patients with colon cancer (Rafter et al., 2007). Studies on animal reported that combining probiotic and prebiotic apply defensive effect against the development of tumor in colon, however, human data sustaining this suggestion are few (Liong, 2008). Moreover, the intervention of synbiotics resulted in significant modification of fecal flora: Lactobacillus and Bifidobacterium were augmented and Clostridium perfringens reduced. In addition, it is imperative to select a mixture of a definite substrate and a microorganism for a synbiotic product that can enhance the advantageous effect when compared to a product including a probiotic or a prebiotic only (Capela et al., 2006; Huebner et al., 2007).

\section{Conclusions and future perspectives}

Substantial improvement has been made in the knowledge to identify and characterize the functional effects of foods and feeds. High-quality health is strongly linked to a good lifestyle, particularly to good quality dietary behavior conforming diet guidelines, the established suggestions and the most recent science on nutrition. Certainly the improvement of the body functions and the progress of well-being and health through a specific diet and the reduction of the risk to develop dietrelated diseases by means of appropriate food choices are priorities for involved parties. These comprise researchers, food/feed industries, consumers and governments. To date, the notion of gut flora modulation is enjoying novel attractiveness and it is essential that human studies are utilized to assess and confirm probiotics, prebiotics and synbiotics. The progress of functional food proposes huge potential for enhancing health and value of life for people. So, it is crucial that the scientific evidence for functional foods be properly substantiated before the possible health benefits are extensively communicated to the consumers. This will make sure the credibility of the claimed benefits of the functional foods. The association between the many disciplines involved in food and nutritional science, consequently, is indispensable for credible and successful innovation in functional food.

\section{Conflict of Interest}

Authors would hereby like to declare that there is no conflict of interests that could possibly arise.

\section{References}

Alkerwi AA (2014). Diet quality concept. Nutrition, 30: 613618.

An YH, Friedman RJ (1997) Laboratory methods for studies of bacterial adhesion. Journal of Microbiological Methods 30: 141-152.

Asher G, Sassone-Corsi P (2015) Time for food: the intimate interplay between nutrition, metabolism, and the circadian clock. Cell 161: 84-92.

Aureli P, Capurso L, Castellazzi AM, Clerici M, Giovannini M, Morelli L, Poli A, Pregliasco F, Salvini F, Zuccotti GV (2011) Probiotics and health: an evidence-based review. Pharmacological Research 63: 366-376.

Bielecka M, Biedrzycka E, Majkowska A, Juśkiewicz J, Wróblewska M (2002) Effect of non-digestible oligosaccharides on gut microecosystem in rats. Food Research International 35: 139-144.

Bigliardi B, Galati F (2013) Innovation trends in the food industry: the case of functional foods. Trends in Food Science \& Technology 31: 118-129.

Brown L, Poudyal H, Panchal SK (2015) Functional foods as potential therapeutic options for metabolic syndrome. Obesity Reviews 16: 914-941.

Capela P, Hay TKC, Shah NP (2006) Effect of cryoprotectants, prebiotics and microencapsulation on survival of probiotic organisms in yoghurt and freeze-dried yoghurt. Food Research International 39: 203-211.

Chen WL, Liang JB, Jahromi MF, Abdullah N, Ho YW, Tufarelli V. (2014) Enzyme treatment enhances release of prebiotic oligosaccharides from palm kernel expeller. BioResources 10: 196-209.

Conway PL (1996) Selection criteria for probiotic microorganisms. Asia Pacific Journal of Clinical Nutrition 5: $10-14$.

Coppens P, Fernandes Da Silva M, Pettman S (2006) European regulations on nutraceuticals, dietary supplements and functional foods: A framework based on safety. Toxicology 221: 59-74.

de Vrese M, Schrezenmeir J (2008) Probiotics, prebiotics, and synbiotics. In: Food Biotechnology, pp. 1-66, Springer Berlin Heidelberg.

Deng YF, Di Liao X, Wang Y, Liang JB, Tufarelli V (2015) Prebiotics mitigate in vitro sulfur-containing odour generation in caecal content of pigs. Italian Journal of Animal Science 14: 132-137. 
Dimer C, Gibson GR (1998) An overview of probiotics, prebiotics and synbiotics in the functional food concept: perspectives and future strategies. International Dairy Journal 8: 473-479.

FAO/WHO (2001) Safety evaluation of certain mycotoxins in food. Food \& Agriculture Organization, vol. 74.

Fernandes CF, Shahani KM (1990) Anticarcinogenic and immunological properties of dietary lactobacilli. Journal of Food Protection 53: 704-710.

Gibson GR, Probert HM, Van Loo JAE, Roberfroid MB (2004) Dietary modulation of the human colonic microbiota: Updating the concept of prebiotics. Nutrition Research Review 17: 257-259.

Gibson GR, Roberfroid MB (1995) Dietary modulation of the human colonic microbiota -introducing the concept of prebiotics. Journal of Nutrition 125: 1401-1412.

Gibson GR, Williams CM (2005) Functional foods. IFIS Publishing.

Gmeiner M, Kneifel W, Kulbe KD, Wouters R, De Boever P, Nollet L, Verstraete W (2000) Influence of a synbiotic mixture consisting of Lactobacillus acidophilus 74-2 and a fructooligosaccharides preparation on the microbial ecology sustained in a simulation of the human intestinal microbial ecosystem (SHIME reactor). Applied Microbiology and Biotechnology 53: 219-223.

González-Herrera SM, Herrera RR, López MG, Rutiaga OM, Aguilar CN, Esquivel JCC, Martínez LAO (2015) Inulin in food products: prebiotic and functional ingredient. British Food Journal 117: 371-387.

Grajek W, Olejnik A, Sip A (2005) Probiotics, prebiotics and antioxidants as functional foods. Acta Biochimica Polonica, 52: $665-671$.

Huebner J, Wehling RL, Hutkins RW (2007) Functional activity of commercial prebiotics. International Dairy Journal 17: 770-775.

Jahromi MF, Altaher, YW, Shokryazdan P, Ebrahimi R, Ebrahimi M, Idrus Z, Tufarelli V, Liang JB (2015) Dietary supplementation of a mixture of Lactobacillus strains enhances performance of broiler chickens raised under heat stress conditions. International Journal of Biometeorology DOI 10.1007/s00484-015-1103-x.

Knorr D (1998) Technology aspects related to microorganisms in functional foods. Trends in Food Science and Technology 9: 295-306.

Kwak NS, Jukes DJ (2001) Functional foods. Part 1. The development of a regulatory concept. Food Control 12: 99107.
Langhendries JP, Detry J, Van-Hees J, Lamboray JM, Darimont J, Mozin MJ, Secretin MC, Senterre J (1995) Effect of a fermented infant formula containing viable bifidobacteria on the fecal flora composition and $\mathrm{pH}$ of healthy full-term infants. Journal of Pediatric Gastroenterology and Nutrition 21: $177-181$

Laudadio V, Lorusso V, Lastella NMB, Dhama K, Karthik K, Tiwari R, Alam GM, Tufarelli V (2015) Enhancement of nutraceutical value of table eggs through poultry feeding strategies. International Journal of Pharmacology 11: 201-212.

Lee Y K, Salminen S (1995) The coming age of probiotics. Trends in Food Science \& Technology 6: 241-245.

Liong MT (2008) Roles of probiotics and prebiotics in colon cancer prevention: postulated mechanisms and in-vivo evidence. International Journal of Molecular Sciences 9: 854863.

Macfarlane SMGT, Macfarlane GT, Cummings JT (2006) Review article: prebiotics in the gastrointestinal tract. Alimentary Pharmacology \& Therapeutics 24: 701-714.

Mark-Herbert C (2004) Innovation of a new product category Functional foods. Technovation, 24: 713-719.

Marteau P, Vesa T, Rambaud JC (1997) Lactose malabsorption. In: Fuller R, ed. Probiotics 2: applications and practical aspects. London: Chapman \& Hall, pp.65-88.

Mattila-Sandholm T, Myllarinen P, Crittenden R, Mogensem G, Fonden R, Saarela M (2002) Technological challenges for future probiotic foods. International Dairy Journal 12: 173-182.

Menrad K (2003) Market and marketing of functional food in Europe. Journal of Food Engineering 56: 181-188

Michalak I, Chojnacka K (2016) Functional Fermented Food and Feed from Seaweed. Fermented Foods, Part I: Biochemistry and Biotechnology, 246.

Milner JA, Roberfroid M (1999) Nutritional properties of inulin and oligofructose. Journal of Nutrition 129: 1395-1397.

Mousavi SM., Seidavi A, Dadashbeiki M, Kilonzo-Nthenge A, Nahashon SN, Laudadio V, Tufarelli V (2015) Effect of a synbiotic (Biomin $\left.{ }^{\circ} I M B O\right)$ on growth performance traits of broiler chickens. European Poultry Science 79. DOI:10.1399/eps.2015.78

Niva M (2007) 'All foods affect health': Understandings of functional foods and healthy eating among health-oriented Finns. Appetite 48: 384-393.

Pandey KB, Rizvi SI (2009) Plant polyphenols as dietary antioxidants in human health and disease. Oxidative Medicine and Cellular Longevity 2: 270-278. 
Paturi G, Butts CA, Bentley-Hewitt KL, Hedderley D, Stoklosinski H, Ansell J (2015) Differential effects of probiotics, prebiotics, and synbiotics on gut microbiota and gene expression in rats. Journal of Functional Foods 13: 204213.

Peiretti PG, Gai F, Brugiapaglia A, Mussa PP, Meineri G (2015) Fresh meat quality of pigs fed diets with different fatty acid profiles and supplemented with red wine solids. Food Science and Technology-Brazil, DOI: https://dx.doi.org/10.1590/1678-457X.6653

Pisulewski P, Kostogrys RB (2003) Functional properties of foods of animal origin and the methods of their assessment. Polish Journal of Food and Nutrition Sciences 12: 65-73.

Rafter J, Bennett M, Caderni G, Clune Y, Hughes R, Karlsson PC, Klinder A, O'Riordan M, O'Sullivan GC, Pool-Zobel B, Rechkemmer G, Roller M, Rowland I, Salvadori M, Thijs H, Van Loo J, Watzl B, Collins JK (2007) Dietary synbiotics reduce cancer risk factors in polypectomized and colon cancer patients. The American Journal of Clinical Nutrition 85: 488496.

Rezaei S, Jahromi MF, Liang JB, Zulkifli I, Farjam, AS, Laudadio V, Tufarelli V (2015) Effect of oligosaccharides extract from palm kernel expeller on growth performance, gut microbiota and immune response in broiler chickens. Poultry Science 94: 2414-2420.

Roberfroid MB (2002) Functional foods: concepts and application to inulin and oligofructose. British Journal of Nutrition 87: 139- 143.

Saarela M, Lähteenmäki L, Crittenden R, Salminen S, MattilaSandholm T (2002) Gut bacteria and health foods-the
European perspective. International Journal of Food Microbiology 78: 99-117.

Sanders ME (1998) Overview of functional foods: emphasis on probiotic bacteria. International Dairy Journal 8: 341-347.

Seno Y, Kariyama R, Mitsuhata R, Monden K, Kumon H (2005) Clinical implications of biofilm formation by Enterococcus faecalis in the urinary tract. Acta Medica Okayama 59: 79-87.

Side C (2006) Overview on marketing functional foods in Europe. Functional Food Network General Meeting.

Siro I, Kapolna E, Kapolna B, Lugasi A (2008) Functional food. Product development, marketing and consumer acceptance - A review. Appetite 51: 456-467.

Stanton C, Ross RP, Fitzgerald GF, Van Sinderen D (2005) Fermented functional foods based on probiotics and their biogenic metabolites. Current Opinion in Biotechnology 16: 198-203.

Tasvac B (1964) Infantile bacterial enterocolitis treatment with Bifidobacterium bifidum. Annals Pediatrics 11: 291-297.

Vella MN, Stratton LM, Sheeshka J, Duncan AM (2013) Exploration of functional food consumption in older adults in relation to food matrices, bioactive ingredients, and health. Journal of Nutrition in Gerontology and Geriatrics 32: 122144.

Vella MN, Stratton LM, Sheeshka J, Duncan AM (2014) Functional food awareness and perceptions in relation to information sources in older adults. Nutrition Journal 13: 44. 